\title{
Managing Environmental Uncertainty: From Conceptual Review to Strategic Management Point of View
}

\author{
Fardis Samsami ${ }^{1}$, Seyed Hamid Khodadad Hosseini ${ }^{1}$, Asadollah Kordnaeij ${ }^{1}$ \& Adel Azar ${ }^{1}$ \\ ${ }^{1}$ Faculty of Management and Economics, Tarbiat Modares University, Tehran, Iran \\ Correspondence: Seyed Hamid Khodadad Hosseini, Faculty of Management and Economics, Tarbiat Modares \\ University, Tehran, Iran. E-mail: khodadad@modares.ac.ir
}

Received: April 29, 2015

doi:10.5539/ijbm.v10n7p215

\author{
Accepted: May 8, 2015 \\ Online Published: June 20, 2015
}

URL: http://dx.doi.org/10.5539/ijbm.v10n7p215

\begin{abstract}
Uncertainty surrounds all aspects of organizations' lives. We rarely find studies in the field of organization and management not mentioned the phenomenon of environmental uncertainty. Despite the ubiquity of studies around the topic, there are many incompatibilities and inconsistencies in the definition and application of the concept. In this paper we try to classify the main issues and controversies around the topic and review some of the outstanding studies in this regard. As the ultimate goal of studying uncertainty in organization is to face it in the choice of appropriate strategies, we also have a brief review on the impacts of environmental uncertainty on organizational strategic decisions and managers' actions. Finally, we refer to some of the frameworks and approaches that are mainly presented in the field of strategic management for dealing with uncertainty, and resolving the strategy paradox between uncertainty and commitment to strategies.
\end{abstract}

Keywords: environmental uncertainty, uncertainty management, strategic management, uncertainty perception

\section{Introduction}

Uncertainty is a phenomenon deeply rooted in our lives and affects many of our choices and decisions. It starts from people's everyday small choices and covers the strategic decisions of multinational corporations. We rarely find studies in the field of organization and management not mentioned the phenomenon of uncertainty. It is because lack of understanding and facing uncertainty in organizational decision-making, cost too much. These costs arise in the form of unforeseen results, negative effects or lost opportunities (Abbott, 2005).

Research in the field of conceptualization, measurement, and dealing with uncertainty is very diverse. As Vecchiato and Roveda (2011) stated, the first attempts to conceptualize uncertainty refers to the first scholars of management (e.g. Knight, 1921; March \& Simon, 1958). They believed that the business environment is substantively instable and its instability creates uncertainty for managers with bounded rationality (Vecchiato \& Roveda, 2011). Over decades, theorists of organization and researchers in the field of strategic management conducted studies and investigations on the concept of environmental uncertainty. This is especially obvious in studies about the relationship between organizations and their environment or studies that present strategic planning models (Milliken, 1987).

Definition of the concept of environmental uncertainty is taken from various perspectives and is generally presented by psychologists and economists. These definitions describe environmental uncertainty mainly in the form of inability to determine the likelihood of future events, lack of information about the cause and effect relationships, inability to accurately predict the implications of the decision, and etc. Milliken (1987) defines uncertainty as the individual's perception of the inability to predict accurately. This inability is due to lack of sufficient data to predict correctly or the sense of inability to distinguish between relevant and irrelevant data (Milliken, 1987).

Some authors use uncertainty and risk interchangeably, but economists such as Mack (1971) distinguished between risk and uncertainty. He believed uncertainty is a wide term and covers risk. According to him: "The risk exists when two or more states are possible and the probability of each of them can be determined with certainty. Uncertainty is used in cases where information is insufficient and observations are irregular. Deep uncertainty exists when the inferential (logical reasons) and experimental (observations) foundations of knowledge are weak." He believes that uncertainty is the complementary of knowledge. In fact, it is the gap 
between what we know and what we need to know to make the correct decisions (Abbott, 2005).

One of the major issues in the field of environmental uncertainty is the presence of different and sometimes conflicting definitions and perspectives. According to Bucko (1994), these definitions include a wide range of concepts from unpredictability to Dynamism and uncontrollability. This makes it difficult to interpret the obtained results and measure uncertainty (Buchko, 1994; McIver, Shimizu, \& Kim, 2009). The multiplicity and heterogeneity of views goes so far that, according to Boyd \& Fulk (1996): "The more a person studies the literature, the more he gets skeptical about the concept of uncertainty, let alone its measurement".

Resolving any discrepancies in understanding uncertainty primarily requires knowledge of various aspects of this concept and development of ideas in the conceptualization. That is why we explore different aspects and classifications of the concept of uncertainty in Section 2 and review the main approaches to uncertainty in Section 3 of this paper. Dewey (1929 in Abbott 2005) suggests that what makes uncertainty real or relevant for individuals are their possible implications or consequences. It is clear that the ultimate goal of studying uncertainty in organization, is to face it in the choice of appropriate strategies. Given that on one hand, strategic decisions are towards future, their consequences are more important than other decisions, a huge ample of organizational resources are allocated to them and returning from them is very expensive, and on the other hand, since future is unpredictable, exploring the effect of uncertainty on organization and managers' reaction is very important. That is why we review some of the effects of uncertainty on the organization and the strategic management process in Section 4. The presence of uncertainty makes us unsure that good decisions can lead to good outcomes, but there are many things to know and many ways to deal with the unknowns. Giving order and structure to the decision-making process, various authors have tried to provide recommendations for the management of uncertainty. In Section 5, we review some general frameworks and approaches for dealing with uncertainty in the field of strategic management.

This paper is an attempt that brings together some major issues and challenges in the field of uncertainty and strategic management which are mainly scattered, and classifies and analyzes them to pave the way for further research to develop and fix challenges and provide more advanced strategies to manage uncertainty.

\section{Environmental Uncertainty}

To understand uncertainty, it is primarily necessary to distinguish between the nature, level and source of uncertainty.

\subsection{Nature of Uncertainty}

Walker et al. (2003) argue that any shortcomings with the ideal state of a system creates uncertainty. This shortcoming may be in the field of information or other fields such as behavior of the players. Two categories of uncertainty are identifiable by nature: 1 . Cognitive uncertainty which is related to the decision maker and is caused by the lack of knowledge and limitations of data and information (Potter, Rosen, \& Johnson, 2012), or complexity (plurality of elements and their high interdependency). This type of uncertainty is reduced by creating knowledge, research and learning. 2. Variability uncertainty which is due to substantive variability of the system, for example, substantive randomness of nature, human behavior, social, economic and cultural dynamics, and technological wonders (Meijer, Hekkert, Faber, \& Smits, 2006). More research does not help eliminating the second type of uncertainty (Walker et al., 2003). This uncertainty may arise from a random effect (random error), or a systematic effect (systematic error). Random errors can be measured by all statistically valid methods, but systematic errors are only measured by scientific judgment that uses available relevant information and statistical reasoning (Potter et al., 2012).

\subsection{Level of Uncertainty}

One of the big mistakes in the perception of uncertainty is the zero and one view. This means that the world is quite certain and we can make accurate predictions about the future, or is completely uncertain and unpredictable. Ignoring uncertainty may lead to strategies that are not resistant against threats and cannot benefit from the opportunities arising from uncertainty. On the other hand, assuming that the world is totally unpredictable, may lead the fact that managers put their analysis away and take strategic decisions solely on instinct (Courtney, Kirkland, \& Viguerie, 1997). The important thing is to identify the level of uncertainty and select an approach of decision-making which commensurate with it (Walker et al., 2003). The level of uncertainty is the amount of uncertainty in each position, which covers a range from certain complete understanding to complete ignorance (Meijer et al., 2006). Walker et al. (2003) used the following terms for naming different uncertainty levels:

- Certainty: ideal state where we know everything;

- Statistical uncertainties: uncertainties describable in statistical terms when clear functional relationships are 
available;

- Scenario uncertainty: Scenario is a potential description of the future development of the system based on coherent assumptions and consistent internal relations. Here, a range of possible outcomes is known but the possibility of the events and the mechanism to achieve them is unknown;

- Recognized ignorance: fundamental uncertainty about the mechanisms and relationships; and

- Total ignorance: it is a deep level of uncertainty in which we do not even know what we do not know.

In another classification, Courtney et al. (1997) identified four levels of uncertainty in this way:

- $\quad$ First level, a clear enough future: At this level, managers can make an identical prediction of the future and develop their strategy accordingly. This prediction is accurate enough to determine the strategic direction.

- Second level, alternate futures: At this level, the consequences are not identified, so it is difficult to predict which outcome will occur, but their occurrence likelihood can be identified to some extent.

- Third level, a range of futures: In this level, a range of potential futures are identifiable, but there is no specific scenario.

- $\quad$ Fourth level, true ambiguity: There are multiple determinants of environmental uncertainty, at this level. Scenarios and even potential consequences of the range are not identifiable and one cannot even identify all the factors that shape the future (Courtney, 2003).

\subsection{Source of Uncertainty}

Uncertainty sources refers to a range of environment that the decision maker is uncertain about (Regan, 2012). To improve the understanding, we should make a distinction between the organization, the transactional environment, and the contextual environment (Abbott, 2005). This classification of the environment is almost consistent with classification of Dell (1958 in Priem, Love \& Shaffer, 2002) into duty and public environments and classification of Milliken (1987) into micro-environment (including competitors, demand, market and supply) and macro environment (state and technological environment). In this regard, Sinding, Anex, and Sharfman (1999), classified the sources of uncertainty faced by companies into two types of internal and external sources. External sources mainly fall in to the following three categories:

- The nature, its future and human problems in this regard including uncertainty about the causal relationship of the environment, the mismatch between the amount of available information about the various elements of the system, and finally the methodological issue that arises from the ways we choose to measure variables.

- The process that leads to establishment and strengthening of the rules. Rules can create uncertainty about current and future operational conditions of companies' environment. Here, the source of change is not only the occurrence of change but also the size and volatility of the rules changing rate.

- The measures that the organization takes in response to environmental uncertainty. These measures affect external actors, competitors and all the stakeholders and may arise from the nature of response options, choices consequences and the value arising from the choice of options.

Internal sources of environmental uncertainty are classified in 3 categories of financial impact, the impact on the organization's values and influences of information processing. Data processing effects are usually referred to difficulty of environmental data analysis resulting from substantive ambiguity and complexity in the analysis of large volumes of ambiguous data (Sinding et al., 1998).

Another view that defines uncertainty equivalent to unpredictability, believe that to understand different types of uncertainty, requires to find out what links the past and the present to the future. Such events are numerous and Mack (1971) believed that the circle of causality is endless and unique to each situation. However, he found four dominant causal factors as: the basic internal dynamic, the external influences, the human factors and strategies, and chance. Each of these factors produce a certain type of uncertainty:

- Casual uncertainty: uncertainty about the underlying causal relationships (physical, economic and social) in a position

- Human and organizational uncertainty: future activities and intentions of the individuals and organizations in a situation that is difficult to predict.

- External uncertainty: uncertainty about a larger social environment and how it affects the position.

- Chance uncertainty: chance events that cannot be recognized (Abbott, 2005). 


\subsection{Combinational Classifications}

Some authors presented classifications with multiple and combinational dimensions, for uncertainty. For example, Dequech (2011) combines the three main distinctions of uncertainty as follows: The first distinction is created between substantive and procedural uncertainty (Dosi \& Egidi, 1991). Substantive uncertainty is due to the lack of information necessary to take decisions. Procedural uncertainty arises from limitations in the computational and cognitive ability of factors in the presence of information. The second distinction is between weak and strong uncertainty. When there is a unique and absolutely reliable probability distribution, the uncertainty is weak and when there is no such distribution, uncertainty is strong. If the strong uncertainty is due to the lack of information, it is substantive and if it results from the conflict between subjective and computational ability or complexity of a situation, it is procedural. Weak uncertainty is always substantive (Dequech, 2000) and is classified in two categories of Knightian Risk (including objective probability) and Savage's Uncertainty (including subjective probability). In the former, probability is a part of the real world, but in the latter, probability indicates way of thinking about the world. The third distinction is created between ambiguity and fundamental uncertainty, both of which are types of strong and substantive uncertainty. Ambiguity means uncertainty about the likelihood of events that are caused by lack of information and knowledge. When the decision maker has such uncertainty, he/she is aware of all possible events, but does not know the probability of each. But the fundamental uncertainty exists when we do not know the list of events and we believe that the future will be built by what people do. According to Dequech (2011), all fundamental uncertainties exist simultaneously with procedural uncertainty. The interdependence of people's decisions create procedural uncertainty about the consequences of the individual's action. The amount of procedural uncertainty changes over time, even if the amount of complexity is not changed; because the computational power of individuals rises over time (e.g. by development of computers) and since this happens for others, the complexity of the interdependence between their decisions rises spontaneously.

It should be noted that the terms ambiguity and uncertainty have also been used in other forms. For example, according to Schrader, Riggs, and Smith (1993) uncertainty occurs when we identify the influencing variables and their relationships and only the value of variables are not identified. Ambiguity is when we do not know the variables or their functional relationships that are needed to change mental models.

\section{General Approaches to Uncertainty}

\subsection{Objective versus Subjective Approaches}

Much of the confusion about the concept of uncertainty is due to the use of this term simultaneously to describe the state of the environment and the person (Buchko, 1994). In organization and management studies, there are generally three approaches to uncertainty measurement: objective measures, perception measures and the mixed approach of the two (Ashill \& Jobber, 2010). Environmental and perceptual measures of uncertainty, are conceptually and operationally different. Objective measures generally study the external phenomenon and the organization environment components in terms of variability. In contrast, perceptual measures are appropriate for examination of managerial behavior and decision-making (Buchko, 1994) and are essential prerequisite to the study of topics such as decision-making, effective leadership, environmental scanning, etc. Perceptual scales allow researchers to consider the company from the perspective of key actors in organization or dominant coalition (McIver et al., 2009).

\subsubsection{Objective Measures of Uncertainty}

In the early modernist thinking, uncertainty was a property of the environment that derived from two powerful forces: complexity and environment variability. Complexity is the heterogeneity of the environment. A complex environment is made up by many customers, consumers and competitors and there are many differences between them. Variability is the turbulence of the environment. A variable environment is faced with a high rate of change (Ashill \& Jobber, 2010). In addition to two dimensions of dynamic-static and complexity- simplicity, Mintzberg (1979) introduced environmental generosity-hostility as a source of uncertainty as well. This dimension is measured by factors such as the availability of labor, competitive hostility and business costs (Ghosh, Bhowmick, \& Guin, 2014).

Objective measures use statistical analysis to infer environmental uncertainty. For example, Anderson and Schmittlein (1984) provided a measure for uncertainty by measuring the expected deviation between the forecasted and achieved sales. Simerly and $\mathrm{Li}(2000)$, also proposed a scale based on the characteristics of the environment (dynamic) according to the standard error of the regression coefficient divided by the mean value of the goods transported in industry (Ashill \& Jobber, 2010). 


\subsubsection{Perceptual Measures of Uncertainty}

The assumption that all the people have common perception about the environment, is under question. So, when research is focused on managerial decisions, environmental perceptions are more important than the environment characteristics. The number of studies that have used this approach to examine and assess the uncertainty is enormous and each of the studies usually have focused on specific aspects of uncertainty (Ashill \& Jobber, 2010).

Burns and Stalker (1961) were among the first people who applied uncertainty concept in the interpretation of contingency theory clearly and systematically. Studying 20 English companies, they obtained general description of uncertainty, but did not provide means to evaluate it (Downey \& Slocum, 1975).

Lawrence and Lorsch (1967) developed Burns and Stalker's research and evaluated the uncertainty related to each of the micro-environments (sale, production and R\&D) with the following three measures (Buchko, 1994): A) lack of work requirements information clarity, B) total uncertainty about the causal relationships and difficulty to get a labor in available limitations; and C) the period for receiving feedback from the results. They collected managers' perception about these components, and obtained three different scores for three types of uncertainty. In their opinion uncertainty was the sum of the scores obtained from the three types of uncertainty. The study found a significant difference between the perceived uncertainties in different industries (Downey \& Slocum, 1975). Downey, Hellriegel, and Slocum (1975) confirmed the validity and reliability of the tool by making modifications to it, i.e. they used the sum of the scores of questions relating to a subject rather than the sum of the scores of micro-environment (Gerloff, Muir, \& Bodensteiner, 1991).

Then Duncan (1972) tried to facilitate using contingency approach in the field of uncertainty by correlating both the complexity and dynamic dimensions of environment with the manager's perception of uncertainty. Using semantic analysis of individuals' saying about uncertainty, he proposed three indexes to measure it: 1. lack of information about environmental factors related to a specific decision-making condition, 2. Lack of awareness about the consequences of a decision, and 3. ability or inability to determine the possibility of a factor's impact on the success or failure of a decision. According to Duncan, the amount of uncertainty perceived in simple-static and complex-dynamic environments are minimum and maximum, respectively. And dynamics in the perceived uncertainty is more important than complexity. Duncan also believed that environmental features depend on perceptions of organization's individuals.

Using objective measures of environment variability, some scholars tried to verify the validity and reliability of perceptual uncertainty measures (Downey et al., 1975), but they found low or partial validity and reliability for these measures. That is because most of the studies have used environmental variability index for validation process, and environment variability evaluation measures is inadequate for this purpose (Gerloff et al., 1991). It means that it is not only the change or rapid rate of change that creates environmental uncertainty, but also unpredictable changes which are the main driver of uncertainty (Milliken, 1987; McIver et al., 2009). Some believe that the increased variability and reliability can simultaneously exist (Eisenhardt, 1989). Some others even believe there is no relationship between variability and uncertainty (McIver et al., 2009). Milliken (1987) argues that there is no need to establish a one-by-one correspondence between the objective indexes of uncertainty and perceived uncertainty indexes, because what people perceive is not necessarily correspondent to the reality. People's perceptions of uncertainty follows the environment perceived features including dynamicity and complexity, individual differences in cognitive processes, total behavioral responses, which arise from the experience of the individual, and social expectations for understanding uncertainty (Downey \& Slocum, 1975).

The result is that using objective and perceptual measures of uncertainty and even different perceptual measures may lead to different results.

\subsubsection{Mixed Measures of Uncertainty}

The multiplicity and diversity of sources and dimensions of uncertainty prompted researchers to provide mixed measures of uncertainty (McIver et al., 2009). Milliken (1987) introduces three types of uncertainty, which together creates the total uncertainty that strategic decision makers are faced with:

1) State uncertainty: the inability to understand the way components of environment change and the relationship of these components with each other (Vecchiato \& Roveda, 2011). This is true for both macro and micro environment of the organization. This uncertainty depends on the environmental characteristics of in which the organization operates.

2) Effect uncertainty: the management inability to predict the nature, amount and time of driving change consequences' impact on the organization. This type of uncertainty refers to the lack of understanding about the 
causal relationships.

3) Response uncertainty: Lack of knowledge about the possible alternatives to answer or inability to predict the consequences of a selected response. When you feel the need for some kind of action, the response uncertainty gets more remarkable. Therefore, top managers of the organization face with such uncertainty when choosing among different strategies or when determining the appropriate response (Milliken, 1987).

Gerloff et al. (1991) argued that in conceptual perspective, the relationship between the components of Milliken' model must be from state uncertainty to effect and then response uncertainty. Ashil \& Jobber (2010) showed that state uncertainty is associated with effect uncertainty and effect uncertainty is related to response uncertainty. It means the perception of uncertainty follows the sequence proposed by Gerloff et al. (Ashill \& Jobber, 2010)

It is worth mentioning that in Milliken's uncertainty classification, after decision is made and implemented for the response, in fact a fourth uncertainty occurs which is related to the consequences or the effectiveness or success of the response. Here we have concerns if the provided response has been achieved its goals. If such an evaluation of decisions is not conducted, decision-making process is flawed, and the organization cannot be sure about achieving the desired outcome. This assessment is as a feedback that helps organizational learning and dealing with future uncertainty (Regan, 2012).

\subsection{Aggregation versus Disaggregation Approaches to Uncertainty}

One of the contentious issues in the measurement of uncertainty is using aggregated or disaggregated measures (McIver et al., 2009). For example, Lawrence and Lorsch and Duncan scales, are aggregated ones that various subscales should be summed up to achieve the total uncertainty. Or as in Miles and Snow's (1978) environmental uncertainty measure, environmental uncertainty is the sum of respondents' predictability rate of six main criteria (suppliers, competitors, customers, financial markets, government and regulatory agencies). On the other side, some authors such as Downey et al. (1975) believe that in aggregated models there is no correlation between the overall uncertainty and these factors, despite the correlation between some subscales and external factors. According to them, the reason is that our understanding of sub-criteria uncertainty is better developed and we should move forward to one-dimensional uncertainty rather than multidimensional one. Milliken also didn't believe in accumulating various indexes, and believed that disaggregated indexes are superior to aggregated ones (Gerloff et al., 1991).

\section{How Uncertainty Affects Organization and Management?}

In previous sections, we generally examined the types of uncertainty and the way of its identification and evaluation. These investigations are accomplished when we get informed of uncertainty effects on organization and more importantly on managers. According to Daft and Weick (1984), organization is an interpretational system that uses three steps of: monitoring or collecting data, interpretation or giving meaning to data, learning or acting based on their perception of the environment. Managers who are in the early stages of the environment monitoring, need to earn a lot of data about environmental events and trends so that they can make the environment more predictable. Once the data is collected, the manager's concern is not only the interpretation of the data, but also how to interpret its meaning and effect on the organization. Finally, in the learning phase, the manager is looking for an action that must be done in response to the environment (Gerloff et al., 1991). Investigation of uncertainty impact on organizations started with contingency approach. The authors then examined the impact of uncertainty through the managers' perception of the environment. In addition to the environmental uncertainty perception, newer authors have examined its relationship with other organizational variables including: strategy, planning, and performance. We continue with a brief description of each of these studies, and the main discussion will focus on the role of uncertainty in the strategic management process.

\subsection{Contingency Approach}

Contingency approaches investigate the environment and fit the organization with the existing reality. For example, Lawrence and Lorsch (1967) found that the different levels of uncertainty in the environment is associated with the need of organizations to differentiate and integrate (Buchko, 1994). Galbraith (1969 in Ellis \& Shpielberg, 2003) also argued that task uncertainty is one of the determinants of information processing rate needed to achieve a certain level of performance.

A systematic attention to the uncertainty concept about the organization, started with its introduction as an independent variable in the structure contingency model. According to this theory, the appropriateness of the organizational structure to environmental uncertainty, leads to its improved function. That is, organic structures in uncertain environments and mechanical structures in static and safe environments are effective. Today, the operational efficiency of this approach is questionable. Because on the one hand, they found that environmental 
uncertainty has multiple dimensions and the appropriation discussed may take different states, and on the other hand, matching organizational structure with environmental uncertainty is time consuming. Some authors introduce organizational learning mechanism as an efficient alternative or complementary to reduce environmental uncertainty. Dodgson (1993) argued that the organization needs learning so that it can adapt to changing and uncertain environment and improve its performance. For renewal and modernization, organizations must be provided with necessary organizational knowledge to keep pace with environmental changes. Increasing the use of learning mechanisms in the organization, reduces the managers' feeling of uncertainty. In addition to data collection, information processing is important in reducing uncertainty. When an organization have no suitable organizational mechanism for data processing, there is a negative relationship between information search and feeling of uncertainty. Also, organizations that operate in more uncertain environments, have less formal learning procedures than those that operate in safer environments. These findings are consistent with the contingency theory, since in higher variability, using formal channels would not be very efficient (Ellis \& Shpielberg, 2003).

\subsection{Uncertainty and Performance}

Early studies on the relationship between environmental uncertainty and performance found that these two have an inverse relationship with each other. Lorenzi, Sims, and Slocum (1981) found evidences that perceived uncertainty leads to reduced performance, but the nature of this relationship is still in question. Downey \& Slocum (1982) also found a negative relationship between perceived uncertainty and management's performance. But Pennings (1975 in Gerloff et al., 1991) found no relationship between perceived uncertainty, performance and structure. Aldag \& Storey (1975 in Gerloff et al., 1991) found that similar levels of uncertainty may lead to different performances. They believed that external and internal uncertainty require flexibility and structural change, respectively. As a result, it is essential to separate these two types of uncertainty. One of the important debates on the impact of uncertainty on performance is the distinction between real environment and manager's perception. Bourgeois (1985) suggests that when there is compliance between the environment, as it really is, and the environment, as it is perceived by top managers, the economic performance of the organization gets higher.

\subsection{Uncertainty and Planning}

Every decision we make and all the negotiations we conduct to reduce uncertainty, are part of the source of uncertainty (Özkan \& Türksen, 2014). Planning is a kind of decision-making by individuals and organizations that contains a longer time horizon for activities and results and requires more thinking about alternatives and their consequences. So, the impact of uncertainty on planning is very important. Planning process is able to present a structured social process to understand and manage uncertainty about future, and spontaneously create uncertainties for individuals and groups involved (process uncertainty or uncertainty arising from the planning). The difference between environmental and process uncertainty is that the environmental uncertainty (at different levels) can be understood by everyone, but the uncertainty of planning process can be understood only by individuals and organizations that are totally involved. When people come together to solve a problem, there is high uncertainty about the interests and intentions of others, the issue that must be resolved and possible means to solve the problem. (Abbott, 2005). Marris (1987) believed that planning means controlling uncertainty with actions to secure future, or providing actions that will be done if certain future events come true. This process creates uncertainty for individuals and organizations involved. Abbott (2005), distinguished between three types of process uncertainty: uncertainty in knowledge of the environment, uncertainty about the intentions of other people and organizations, and uncertainty about appropriate value judgments. This is somehow close to the results of Friend and Jessop's classic study on the perceptions of state workers and policy makers of the uncertainty. They identified three dimensions of uncertainty that affect the decision-making process as: Working Environment Uncertainty (UE), Guiding Values (UV), and Choices and Related Agendas (UR) (Abbott, 2005).

\subsection{Uncertainty and Strategic Management}

Miller (1988) suggests that the relationship between the perceived uncertainty and strategy is more important than other parameters (Gerloff et al., 1991). Since the managers' perceptions are their strategic choices basis, the results that companies obtain are largely dependent on the managers' perception (Priem et al., 2002). Litschert and Bonham (1979) showed that the companies perceiving different strategic challenges offer different responses, but companies perceiving the same strategic challenges, do not necessarily have the same strategic response. This suggests that the perception of the environment is more important than its physical properties to determine the organizational behavior. This conclusion is consistent with Child (1972) claiming that the strategic behavior is largely following the ideological values of the dominant coalition. Also, the amount of the organizations free 
sources, differences in psychological characteristics, differences in the ability to acquire resources, different organizational structures, divergent capacities, and different goals can determine the extent that ideological values influence the choice of strategic responses (Litschert \& Bonham, 1979).

During the stage of strategy formulation, perceptions and cognitive style of management plays an important role in defining the situation and the proposed solution. Managers who operate in the same environment have different perceptions of their uncertainty and they must share their information, opinions and perceptions (Gerloff et al., 1991). In addition, managers' perceptions of uncertainty change over time and are easily influenced by events in the organizational environment (Buchko, 1994).

\subsubsection{Impact of Different Types of Uncertainty on Strategic Management}

It is clear that different types of uncertainty have different impacts on the strategic management process. According to Vecchiato and Roveda (2011), if environmental changes lead to fundamental impacts on the business model (including competitors, suppliers, customers, alternative products, new-comers) and presentation of completely new products and activities in the value chain, companies need to re-identify the boundaries of their business. In such circumstances, called boundary uncertainty, using techniques such as scenario, roadmap drawing and etc. is meaningless, and a kind of learning process should be defined for re-identifying new business boundaries. It is after boundary determination that decision makers can use such techniques in order to understand state, effect and response uncertainties.

Managers who experience more state uncertainty, spend more time and resources for environmental scanning compared to managers who feel they understand the environment. In this situation, due to the lack of complete understanding of the environment and rational evaluation capacity of the available options, the organization may turn to general strategies to protect the main activities of the organization from sudden environmental changes. Some managers may turn to discrimination strategies to reduce the vulnerability of the organization to the environment. Effect uncertainty is mostly determined in the phase of environmental opportunities and threats analysis. To make the necessary driver available for the organization to search for a strategic response, or to invest on the effect of an event, it should know with some degree of confidence that the event will affect the environment. Therefore, if managers experience a high effect uncertainty, they will spend a lot of time in the phase of opportunities and threats analysis. This requires judgment on the significance of environmental change effects on the organization. Some people believe that when this kind of uncertainty is large, strategic planning becomes paralyzed, but others believe that it is possible to turn to contingency plans.

Managers have different reactions to the response uncertainty. Some people turn to imitate others' strategic responses. If an incorrect response costs high, implementing strategy is postponed until suitable alternatives and the ability to make an accurate assessment are provided. (Milliken, 1987). Ashill and Jobber (2010), argue that state and effect uncertainty affect the pace and nature of response to changes. When state and effect uncertainty are low, responses to opportunities and threats are expected to be quick and decisive. But when the two are high, responses are expected to be slow and cautious. Dependence to processes of strategic planning may influence managers' confidence about the way of responding to external environment changes. That is, whether the organization is conducting an analysis of competitors and strategic planning process, affects the perception of response uncertainty (Ashill \& Jobber, 2010).

According to Milliken, increasing perceived uncertainty deals with increasing diversification strategies. This means that the identification and use of new products and processes are ways to reduce the environmental impacts such as instability and unpredictability. Using these two criteria, contains only a certain type of variation that is applicable when customers' preferences are immutable or unpredictable or competitors are innovative and create uncertainty. But when there is uncertainty in supplier, government, finance and union, the variety of products and processes does not help much, and using criteria such as overall variety of strategies is more appropriate (Buchko, 1994). From another point of view, Miller and Shamsie (1999) stated that the state uncertainty increases the diversity of products, while effect and response uncertainty reduce it (Ashill \& Jobber, 2010).

\section{Managing Uncertainty}

One of the issues in the choice of approach to managing uncertainty is the employee's and organization's attitude to this phenomenon. People may be inclined to avoid or embrace uncertainty. People who embrace uncertainty, find it challenging, desirable, and helpful and do not try to artificially remove the ambiguities and contradictions. People who avoid uncertainty, try to get away from complexities, new things and ambiguous structures. Organizations as well as the employees may tend to avoid uncertainty with inflexible strategic planning, indiscriminate use of consultants and strict control procedures, or embrace it by encouraging meaningful 
dialogues, fostering innovation and remove emphasis from planning processes. In this regard, Clampitt, Williams and Korenak (2000) provided a matrix of uncertainty management. This matrix is the result of the contrast between two dimensions of the employees' uncertainty tolerance level and the willingness of organization to embrace uncertainty. In the first quarter (Status Quo Climate), both the employees and organization avoid uncertainty and employees tend a little to wonder. In the second quarter (Unsettling Climate) employees seek reassurance, but organization covers a lot of uncertainty. Therefore, employees feel uncomfortable and may drown in the turbulent business environment. In the third quarter (Stifling Climate), employees follow uncertainty, but organization avoids it. The result is that employees feel throbbing. In the fourth quarter (Dynamic Climate), both employee and the organization welcome uncertainty. As a result, the space of the organization is dynamic, energetic and constantly changing (Clampitt et al., 2000). A scheme of the matrix is shown in Figure 1.

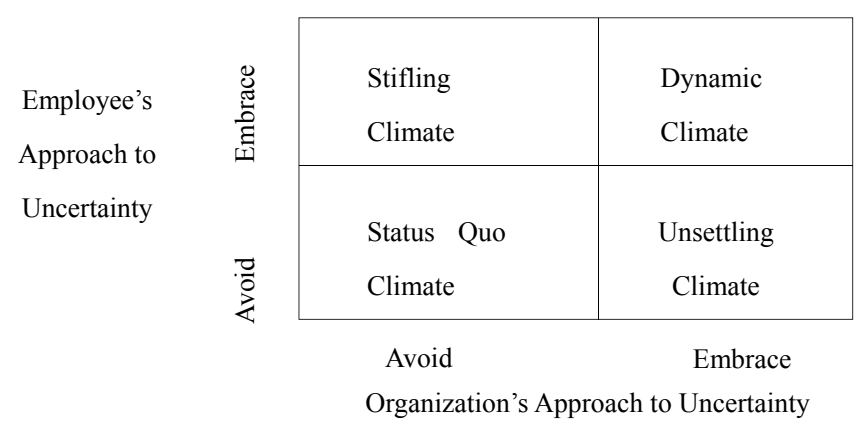

Figure 1. The uncertainty management matrix (Clampitt et al., 2000)

Many scholars and practitioners believe that successful companies are the ones that commit their resources and abilities to strategies that are inimitable. As the commitments are made based on beliefs about the future, and in the presence of uncertainty the future is unpredictable, if the expected future won't come true, those commitments may lead to company failure. So, as Raynor (2007) stated, the strategy paradox arises from the collision of uncertainty and commitment. In the following sections we review Collis matrix, which suggests four approaches to uncertainty management by adjusting way and the time of commitment to resources. Then we refer to different strategic postures that the companies can adopt in face of uncertainty, and finally we point out strategic flexibility and foresight as two solutions that can help resolving the mentioned strategy paradox, and point out some methods for each.

\subsection{Collis' Generic Approaches to Uncertainty}

Collis (1992) provided four general strategic approaches to the management of uncertainty through which companies can achieve desirable balance of risk and return. Collis' matrix has two dimensions: time and amount of investment. In the dimension of investment time, the investment choices are made earlier or later. It is clear that earlier investment is vulnerable to unpredictable consequences, and in delayed investments, uncertainty may be resolved until that time. The dimension of investment volume contains both the number of investments and the number of options that will open with the investment. Using either of these approaches depends on the nature of the uncertainty, the economy of industry and the competitiveness state. In general, delaying investment increases flexibility, because it keeps options open and makes it possible to make decisions due to circumstances. However, this delay is achieved at the expense of losing the opportunity to outshine the competition and create competitive advantage. Four approaches of Collis, shown in Figure 2, are as follows: 
Investment Timing

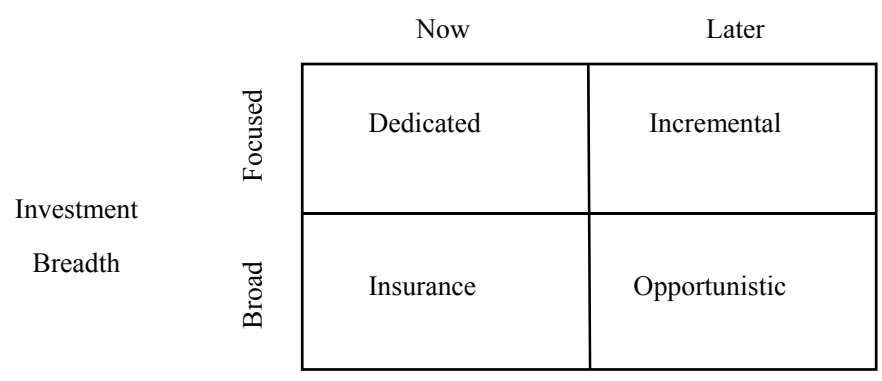

Figure 2. Collis' generic approaches to uncertainty (Collis, 1992)

1) Insurance: By commitment to multiple resources at present time, this approach guarantees the company's returns under all predictable futures. Its main problems are the middle performance risk and lack of differentiation in a specific strategy as well as the high cost. When the number of uncertainties are few, but the range of outcomes is broad, and also the company possesses a competitive advantage, this strategy is appropriate.

2) Dedicated: This approach dedicates all its resources to a strategy at the time being. If uncertainty is resolved in a way that the company's strategy assumed, many benefits can be achieved, otherwise the company will have noticeable loss. Also, it is possible for competitors to imitate the strategy and so it is a good strategy when the number of uncertainties are few and the range of outcomes is narrow.

3) Incremental: delaying investment until the removal of major uncertainty, this method reduces risk. Although the strategy is outlined at the beginning, but its continuation depends on time passage. This approach is appropriate when the number of uncertainties are many, but the range of outcome is narrow.

4) Opportunistic: It almost means to negate the strategy. That strategy is not predetermined and is adopted by removing the uncertainty and opening and closing of opportunities. In this approach, investments are usually short-term and fixed costs are reduced in favor of variable costs. This approach is suitable when the number of uncertainties are many and the range of outcomes is broad, and the company lacks a source of competitive advantage. (Collis, 1992)

\subsection{Strategic Postures in Facing Uncertainty}

Courtney et al. (1997) argued that a company can choose one of the three strategic postures in facing with uncertainty: shaping, adapting, or reserve the right to play. Shapers are to change the industry structure by their own contrivance and create new market opportunities; adaptors accept the industry structure and changes as it is and react to the opportunities that the market provides. Reserving the right to play is a certain type of adapting and can be used only in the higher levels of uncertainty. In this posture, gradually investment is conducted and allows the company to wait until the environmental uncertainty is reduced and then develop the strategy. A posture is not a complete strategy, because it defines the strategic intention but does not set the actions that are necessary to ascertain the intention. Three types of action used to implement the strategy under uncertainty are: 1 . big bets, are big commitments that result in benefit in some scenarios and in some others lead to significant losses. Shaping strategies usually require large bets. 2. Options are designed to maintain large profits in the event of a best-case scenario and minimize losses in the event of a worst case scenario. More options require a relatively low initial investment so that the company could return or increase investment after market developments. Those who keep their right to act, rely entirely on options. 3. No-regret moves, are moves that make profits in any case, no matter what happens. Managers often focus on these moves, such as reducing costs, gaining competitive intelligence or other skills (Courtney et al., 1997).

\subsection{From Adaptation to Strategic Flexibility}

One of the possible responses to uncertainty is adaptation. Rapid changes in the world, increase the need for rapid and successful adaptation. Businesses need to be enough flexible to take advantage of opportunities in the uncertain future and deal with the threats. They should be able to change themselves to be coordinated with the needs of the environment in which they compete. However, adaptation is useful when the organization's change rate is the same as the environment change rate. Since the organization interact with different environments, it 
cannot be adapted to different and various rates of change. As a result, despite its various benefits, adaptation application is limited. On the other hand, the risk of adaptation is that the organization choses its strategy so flexible that there is no functional difference with the lack of strategy. So, highly adaptable organizations need a something to be able to cope with unpredictable demands of the environment (Rayor, 2007).

Das (1995) argues that for many managers who seek to adjust their organizational capabilities with the environment, strategic flexibility is a complementary approach, and prepares the organization to face with the changing environment and exploit the opportunities effectively. The strategic flexibility is the ability of a company to respond to uncertainties through adapting the objectives with changing conditions, or act proactively (Brozovic \& Nordin, 2011) to make the change, using the knowledge and capabilities of the organization. Approaches and models available for strategic flexibility are numerous. One of the most useful ones which is especially designed for managing uncertainty, is the Raynor (2007) strategic flexibility framework, which composed of the following four steps:

1) Anticipate: anticipation is not predicting the future, but to create a better understanding of possible futures and their applications. Scenario analysis is an essential tool in this process.

2) Formulate: at this stage, we must develop an optimal strategy for each scenario and compare strategies among the scenarios. The common elements of scenarios are called core elements and parts of the strategies that change with the changing scenario are named contingency elements.

3) Accumulate: at this stage, the main elements of the strategies are implemented immediately and a team is formed to identify the real options associated with each of the contingency factors. The result of this stage is the collection of options that give the company strategic flexibility.

4) Operate: at this stage, the team must constantly check the environment to determine which scenario is closer to the future. The team must review the optimal strategy for the scenario to see which option must be exercised and which on must be abandoned (Rayor, 2007).

\subsection{From Prediction to Foresight}

One of the inseparable elements of strategy is future. Future contains uncertainty and researchers and experts have been trying many years to predict future and formulate strategies based on estimated results by different kinds of models and techniques. Unfortunately it is not possible to have exact predictions about future, as it is necessary for strategic plans (Rayor, 2007). Therefore, if we change prediction instead of point by point estimations toward real perception of technological, political, economics, and competitive forces, it will stay valuable (Collis, 1992). Organizations' experiences teach them how to look on future to face with changes and to focus on greater processes and basically principles more than attempt to predict exact future scenario. In this way they can distinguish main uncertainties from simple evidences, by means of logic thinking (Collis, 1992). Such though is possible under the light of foresight in organization.

Foresight has two main tasks: First, environmental scanning and identifying new events and drivers of change and second, presenting future-based techniques and measures to identify the drivers of change based on probability (state uncertainty), their impact on the organization (effect uncertainty) and the most important responses (response uncertainty) (Vecchiato \& Roveda, 2011). One of the best and most reliable descriptions of the future is based on the concept of "memory of the future". Ingvar believes that human brain is always building alternatives for time paths. The set of these paths of time creates memory of the future. Then, human brain stores the paths of different time. The more time paths saved, the more we can recognize changes in the external environment and get their meanings (Vecchiato \& Roveda, 2011). It means that foresight combines forecasting and readiness with a deep understanding (Costanzo \& MacKay, 2009) and thereby promotes the capability of understanding and dealing with uncertainty.

\subsection{Methods}

Scholars have presented numerous methods and techniques to face different types and levels of uncertainty in various environments. As a complementary part to the previous sections we refer to two categories of methods:

1) Methods based on strategic flexibility: These methods allow variations in strategies when facing different states of the future. Some of the popular techniques in this category are: Weak signals management, (Ansoff, 1975); Strategic issues approach (Stacey, 1992); dynamic capabilities (Teece et al., 1997); Strategy as options on the future (Williamson, 1999); real options (Luehrman, 1998); and etc. On the other hand, many academicians and practitioners persist on strategies that focus on rigidity and robustness to deal with uncertainties. A robust strategy is the one that is viable in the presence of any state of the future. Robust decision making (Lempert et al., 2003); strategic intent (Hamel, \& Prahalad, 1989); change impact analysis (Hough et al., 1997); assumption 
based planning (Dewar, 2002); scenario based planning (Mandel \& Wilson, 1993); and uncertainty sensitive analysis (Davis, 2003) are some methods that persist on robustness (Khodadad et al., 2011).

2) Foresight methods: This group include a wide variety of quantitative and qualitative techniques, and fall into two main categories:

- Exploratory methods: their main question is "what is possible or likely to happen based on predictions". Methods such as environmental scanning, trend impact analysis, cross impact analysis, agent modeling, road mapping, and causal layered analysis are some examples.

- Normative methods: usually reflect organization needs and therefore are goal-oriented. Their main question is "what we should do"? Some of the popular methods in this category are: relevance trees, morphological analysis, and technological sequence analysis.

There are also various techniques that can be explorative and normative simultaneously, such as: text mining, Delphi, scenarios, future wheels, and etc. (Gordon \& Glenn, 2004).

\section{Conclusion}

One of the great challenges of our times that surrounds all aspects of our personal and organizational life is the environmental uncertainty; that is why many attempts have been made to conceptualize it. Downey and Slocum (1975) argue that the term uncertainty is so pervasive that its meaning seems obvious to everyone, while there are many incompatibilities and inconsistencies in the definition and application of this concept. In this study we tried to classify the main issues and controversies around the topic and review some of the outstanding studies in these regards. Here is a summary of challenges about the concept of uncertainty:

- Definitions and key elements of environmental uncertainty are somehow confusing; (McIver et al., 2009). To resolve this issue, many authors have tried to separate three topics of nature, level and source of uncertainty.

- The term uncertainty is simultaneously used to describe the organization's environment state, and expressing the individual states that understands the lack of information about the environment. The former view means that uncertainty can be explained by the objective characteristics, and the latter means that uncertainty is only meaningful in the viewer's eyes, and therefore must be studied as a perceptual phenomenon. (Milliken, 1987).

- Uncertainty measuring instruments, mainly have weak reliability and validity (Milliken, 1987).

- Disaggregation and aggregation related to the uncertainty lead some authors to use the combined measures of uncertainty, but put some others diligently on the position that different types of uncertainty should be studied separately. (McIver et al., 2009).

- Understanding uncertainty is epistemologically biased. Since uncertainty is an approach about how we know what we know, we are mainly biased in predicting the consequences of actions, using intuition and understanding the environment (Özkan \& Türksen, 2014).

- Although the social process aspect in uncertainty is so important, the literature lacks enough studies in this field. Organizational uncertainty is not a simple sum of individuals' perception. (Downey \& Slocum, 1975) Individuals and groups involved, for any action, must understand uncertainty, talk about it and agree on it (Abbott, 2005).

As we emphasized earlier, studying the effect of uncertainty on organizations and how managers deal with it is crucial. Each analysis should focus on individuals who deal with most important decisions and also the different roles they have in the organization. Therefore, considerations relating to the task environment and the general environment are essential simultaneously (Downey \& Slocum, 1975). Research on the relationship between uncertainty and organizational variables began with the study of the contingency effects of the environment on the organization. Then authors began to examine the impact of uncertainty on the organization through managers' perceptions. More recent authors, in addition to environmental uncertainty perception, examined its relationship with other organizational variables including: strategy, planning, and performance. In the meantime, according to various authors, the study of the relationship between uncertainty and strategic management is more important, because it has more important implications for the organization as well as influencing other organizational variables. Since the managers' perceptions are the basis for their strategic choices and perceptions of managers about uncertainty varies greatly, the results that companies achieve, depends on managers' different perceptions outcome. It is clear that these perceptions vary depending on the level and type of uncertainty.

Perspective and actions of organizations towards uncertainty include a wide range, from uncertainty as an all-out threat and avoiding it entirely, to understanding the uncertainty as an opportunity and embracing it. Such measures may take proactive or reactive forms. Different authors, especially in the field of strategy, have presented different solutions and frameworks for dealing with uncertainty. In this paper we tried to have a brief 
review on these frameworks. Especially, we focused on solutions that might help to resolve the paradox between uncertainty and commitment. We reviewed Collis matrix, which suggests four approaches to uncertainty management by adjusting way and the time of commitment to resources. Then we referred to different strategic postures that the companies can adopt in face of uncertainty, and finally we pointed out strategic flexibility and foresight as two solutions that can help resolving the mentioned strategy paradox.

\section{References}

Abbott, J. (2005). Understanding and managing the unknown, the nature of uncertainty in planning. Journal of Planning Education and Research, 24, 237-251. http://dx.doi.org/10.1177/0739456X04267710

Anderson, E., \& Schmittlein, D. C. (1984). Integration of the sales force: An empirical examination. The Rand Journal of Economics, 15(3), 385-395.

Ansoff, I. (1975). Managing Strategic Surprise by response to weak Signals. California Management Review, 18(2), 21-33.

Ashill, N. J., \& Jobber, D. (2010). Measuring state, effect, and response uncertainty: Theoretical construct development and empirical validation. Journal of Management, 36(5), 1278-1308. http://dx.doi.org/10.1177/0149206308329968

Boyd, B. K., \& Fulk, J. (1996). Executive scanning and perceived uncertainty: A multidimensional model. Journal of Management, 22(1), 1-21. http://dx.doi.org/10.1177/014920639602200101

Brozovic, D., \& Nordin, F. (2011). Servitization as Strategic Flexibility: Insights from an Exploratory Study. Nordic Academy of Management Conference 2011, Stockholm, 22-24.

Buchko, A. A. (1994). Conceptualization and measurement of environmental uncertainty: An assessment of the Miles and Snow perceived environmental uncertainty scale. The Academy of Management Journal, 37(2), 410-425. http://dx.doi.org/10.2307/256836

Bums, T., \& Stalker, G. (1961). The Management of Innovation. Chicago: Quadrangle Books.

Child, J. (1972). Organizational structure, environment and performance: The role of strategic choice. Sociology, 6, 1-22. http://dx.doi.org/10.1177/003803857200600101

Clampitt, Ph. G., Williams M. L., \& Korenak, A. (2000). Managing organizational uncertainty: Conceptualization and measurement. International, Communication Association Conference: San Diego (CA).

Collis, D. (1992). The strategic management of uncertainty. European Management Journal, 10(2), 125-135. http://dx.doi.org/10.1016/0263-2373(92)90060-H

Costanzo, L. A., \& MacKay, R. B. (2009). Handbook of Research on Strategy and Foresight. Cheltenham: Edward Elgar Publishing Limited.

Courtney, H. (2003). Decision-driven scenarios for assessing four levels of uncertainty. Strategy and Leadership, 31(1), 14-22. http://dx.doi.org/10.1108/10878570310455015

Courtney, H., Kirkland, J., \& Viguerie, P. (1997). Strategy under uncertainty. Harvard Business Review, November-December, 66-79.

Daft, R. L., \& Weick, K. E. (1984). Toward a model of organizations as interpretation systems. Academy of Management Review, 9, 284-295. http://dx.doi.org/10.5465/AMR.1984.4277657

Das, T. K. (1995). Managing strategic flexibility: key to effective performance. Journal of General Management, 20(3), 60-75.

Davis, P. K. (2003). Uncertainty-Sensitive Planning. In Johnson, S. E., Libicki, M. C., and Treverton, G. F. (Eds.), New Challenges, New Tools for Defense Decision making, Santa Monica. Calif.: RAND Corporation.

Dequech, D. (2000). Fundamental Uncertainty and Ambiguity. Eastern Economic Journal, 26(1), 41-60.

Dequech, D. (2011). Uncertainty: A typology and refinements of existing concepts. Journal of Economic Issues, 16(3), 621-640. http://dx.doi.org/10.2753/JEI0021-3624450306

Dewar, J. A. (2002). Assumption-Based Planning: A Tool for Reducing Avoidable surprises. Cambridge UK: Cambridge Press.

Dodgson, M. (1993). Organizational learning: A review of some literatures. Organization Studies, 14(3), 375-394. 
http://dx.doi.org/10.1177/017084069301400303

Dosi, G., \& Egidi, M. (1991). Substantive and procedural uncertainty-An exploration of economic behavior in changing environments. Journal of Evolutionary Economics, 1(2), 145-168.

Downey, H. K., \& Slocum, J. W. (1975). Uncertainty: Measures, research, and sources of variation. The Academy of Management Journal, 18(3), 562-578. http://dx.doi.org/10.2307/255685

Downey, H. K., Hellriegel, D., \& Slocum, J. W. (1975). Administrative Science Quarterly, 20(4), 613-629.

Duncan, R. B. (1972). Characteristics of organizational environments and perceived environmental uncertainty. Administrative Science Quarterly, 17, 313-327.

Eisenhardt, K. M. (1989). Making fast strategic decisions in high velocity environments. Academy of Management Journal, 32(3), 543-576. http://dx.doi.org/10.2307/256434

Ellis, Sh., \& Shpielberg, N. (2003). Organizational learning mechanisms and managers' perceived uncertainty. Human Relations, 56(10), 1233-1254. http://dx.doi.org/10.1177/00187267035610004

Gerloff, E. A., Muir, N. K., \& Bodensteiner, W. D. (1991). Three components of perceived environmental uncertainty: An exploratory analysis of the effects of aggregation. Journal of Management, 17(4). 749-768. http://dx.doi.org/10.1177/014920639101700408

Ghosh. S., Bhowmick, B., \& Guin, K. K. (2014). Perceived environmental uncertainty for startups: A note on entrepreneurship research from an Indian perspective. Technology Innovation Management Review, 4(8), 27-35. http://timreview.ca/article/820.

Gordon, T. J., \& Glenn, J. C. (2004). Integration, comparisons, and frontier of futures research methods. EU-US seminar: New Technology Foresight, Forecasting \& Assessment Methods, Seville.

Hamel, G., \& Prahalad, C. K. (1989). Strategic intent. Harvard Business Review, 20(3), 45-52.

Hough, G. W., Rawlings, D. A., \& Turner, M. F. (1997). Pre-production Quality Assurance for Healthcare Manufacturers. Interpharm Press.

Khodadad Hosseini, S. H., Hamidizadeh, M. R., Hoseini, S. M., \& Lashkarboloki, M. (2011). Designing the process model of robust strategy under uncertainty. Journal of Strategic Management Studies, 2(5), 83-109.

Lawrence, P., \& Lorsch (1967). Organization and environment. Boston: Harvard Business School.

Lempert, R. J., Groves, D. G., Popper, S. W., \& Bankes, S. C. (2006). A General, Analytic Method for Generating Robust Strategies and Narrative Scenarios. Management Science, 52(4), 514-528. http://dx.doi.org/10.1287/mnsc. 1050.0472

Litschert, R. J., \& Bonham, T. W. (1979). Strategic responses to different perceived strategic challenges. Journal of Management, 5(1), 91-105. http://dx.doi.org/10.1177/014920637900500106

Lorenzi, P., Sims Jr, H. P., \& Jr. Slocum, J. W. (1981). Perceived environmental uncertainty: An individual or environmental attribute. Journal of Management, 7(2), 27-41.

Luehrman, T. A. (1998). Strategy as a portfolio of real options. Harvard Business Review, September-October 1998 issue.

Mack, R. (1971). Planning on uncertainty: Decision making in business and government administration. New York: Wiley Interscience.

Mandel, T. F., \& Wilson, I. (1993). How companies use scenarios: Practice and prescription. SRI Business Intelligence Programme Report R822.

Marris, P. (1987). Meaning and action: Community planning and conceptions of change (2nd ed.). London: Routledge and Kegan Paul.

McIver. D., Shimizu, K., \& Kim, B. (2009). A critical review of the environmental uncertainty literature since 1987. The University of Texas at San Antonio, college of Business Working Paper Series, Wp\# 0067MGT-110-2009.

Meijer, I. S. M., Hekkert, M. P., Faber, J., \& Smits, R. E. H. M. (2006). Perceived uncertainties regarding socio-technological transformations: Towards a typology. International Journal of Foresight and Innovation Policy, 2(2), 214-240. http://dx.doi.org/10.1504/IJFIP.2006.009316

Miles, R. E., \& Snow, C. C. (1978). Organizational strategy, structure, and process. New York: McGraw-Hill. 
Miller, D. (1988). Relating Porter's business strategies to environmental structure: Analysis and performance implications. Academy of Management Journal, 32, 280-308. http://dx.doi.org/10.2307/256549

Miller, K. D., \& Shamsie, J. (1999). Strategic responses to three kinds of uncertainty: Product line simplicity at the Hollywood film studios. Journal of Management, 25(1), 97-116. http://dx.doi.org/10.1177/014920639902500105

Milliken, F. J. (1987). Three types of perceived uncertainty about the environment: State, effect, and response uncertainty. The Academy of Management Review, 12(1), 133-143. http://dx.doi.org/10.5465/AMR.1987.4306502

Mintzberg, H. (1979). The Structuring of Organizations: A Synthesis of the Research. Prentice-Hall.

Özkan, I., \& Türksen, I. B. (2014). Uncertainty and fuzzy decisions. In Banerjee, S., Sule Ercetin, S., \& Tekin, A. (Eds.), Chaos theory in politics understanding complex systems. Springer Science + Business Media Dordrecht. http://dx.doi.org/10.1007/978-94-017-8691-1_2

Potter, K., Rosen, P., \& Johnson, Ch. R. (2012). From quantification to visualization: A taxonomy of uncertainty visualization approaches. In Uncertainty quantification in Scientific Computing IFIP Advances in $\begin{array}{lllll}\text { Information } \quad \text { and } & \text { Communication 26-249. }\end{array}$ http://dx.doi.org/10.1007/978-3-642-32677-6_15

Priem, R. L., Love, G. L., \& Shaffer, M. A. (2002). Executives' perceptions of uncertainty sources: A numerical taxonomy and underlying dimensions. Journal of Management, 28(6), 725-746. http://dx.doi.org/10.1177/014920630202800602

Raynor, \& Michael, E. (2007). The strategy paradox: Why commitment to success leads to failure (and what to do about it). New York: Doubleday.

Regan, P. (2012). Making sense of uncertainty: An examination of environmental interpretation. International Journal of Business and Management, 7(6), 18-29. http://dx.doi.org/10.5539/ijbm.v7n6p18

Schrader, S., Riggs, W. M., \& Smith, R. P. (1993). Choice over uncertainty and ambiguity in technical problem solving. Journal of Engineering and Technology Management, 10, 73-99.

Simerly, R. L., \& Li, M. (2000). Environmental dynamism, capital structure and performance: A theoretical integration and an empirical test. Strategic Management Journal, 21, 31-55. http://dx.doi.org/10.1002/(SICI)1097-0266(200001)21:1<31::AID-SMJ76>3.0.CO;2-T

Sinding, K., Anex, R., \& Sharfman, M. (1998). Environmental uncertainty, corporate strategy and public policy. The Graduate Management Review, 1, 1-18.

Stacey, R. D. (1992). Managing the unknowable: Strategic boundaries between order and chaos in organizations. Jossey-Bass Publishers.

Syrett, M., \& Devine, M. (2012). Managing uncertainty: Strategies for surviving and thriving in turbulent times. London: The Economist in association with Profile Books Ltd.

Teece, D., Pisano, G., \& Shuen, A. (1979). Dynamic capabilities and strategic management. Strategic Management Journal, $18(7) \quad 509-533$. http://dx.doi.org/10.1002/(SICI)1097-0266(199708)18:7<509::AID-SMJ882>3.0.CO;2-Z

Vecchiato, R., \& Roveda, C. (2011). Uncertainty, foresight, and strategic decision making: Evidence from leading companies. Forth International Seville Conference on Future-Oriented Technology Analysis (FTA): FTA and Grand Societal Challenges-Shaping and Driving Structural and Systemic Transformations, Seville, 12-13 May 2011.

Walker, W. E., Harremoes, P., Rotmans, J., Van Der Sluijs, J. P., Van Asselt, M. B. A., Janseen, \& Krayer Von Krauss, M. P. (2003). Defining uncertainty: A conceptual basis for uncertainty management in model-based decision support. Integrated Assessment, 4(1), 5-17. http://dx.doi.org/10.1076/iaij.4.1.5.16466

Williamson, P. J. (1999). Strategy as Options on the Future. Sloan Management Review, 40(3), 117-126.

\section{Copyrights}

Copyright for this article is retained by the author(s), with first publication rights granted to the journal.

This is an open-access article distributed under the terms and conditions of the Creative Commons Attribution license (http://creativecommons.org/licenses/by/3.0/). 